Programa de Pós-Graduação em Engenharia de Produção - PPGEP
Laboratório de Qualidade de Vida - LaQVida
Universidade Tecnológica Federal do Paraná - UTFPR
Ponta Grossa - PR - Brasil
v. 05, n. 02 , abr./jun. 2013, p. . 67-70

DOI: $10.3895 / \mathrm{S} 2175-08582013000200008$

\title{
Entrevista realizada com Luiz Alberto Pilatti
}

\author{
Camila Lopes Ferreira \\ Instituto Federal do Paraná - IFPR - Paranaguá - Brasil \\ camila.ferreira@ifpr.edu.br
}

\begin{abstract}
Luiz Alberto Pilatti é Professor da Universidade Tecnológica Federal do Paraná - UTFPR. Licenciado em Educação Física - Universidade Estadual de Ponta Grossa - UEPG (1989), Mestre em Educação - Universidade Metodista de Piracicaba - UNIMEP (1995) e Doutor em Educação Física - Universidade Estadual de Campinas - UNICAMP (2000). Exerce o cargo de vice-reitor na UTFPR desde 2012. Professor do Programa de Pós-Graduação em Engenharia de Produção, câmpus Ponta Grossa, onde orienta teses e dissertações na linha de pesquisa Gestão do Conhecimento e Inovação. Líder do Grupo de Pesquisa Gestão de Recursos para o Ambiente Produtivo. Editor da Revista Brasileira de Qualidade de Vida. É Pesquisador do CNPq desde 2009. Possui trabalhos publicados em livros e periódicos nacionais e internacionais.
\end{abstract}

Ressalta-se que foi mantida a entrevista na íntegra, visando preservar a originalidade do depoimento gentilmente oferecido pelo entrevistado, o qual agradecemos enormemente de antemão.

\section{Como surgiu a Revista Brasileira de Qualidade de Vida?}

Sou professor do Programa de Pós-Graduação em Engenharia de Produção, no câmpus Ponta Grossa, da Universidade Tecnológica Federal do Paraná. Vinculado ao programa, lidero o Grupo de Pesquisa Gestão de Recursos Humanos para o Ambiente Produtivo. Em meados da década passada, na linha em que atuo, orientei alguns trabalhos de mestrado que tinham como temática a qualidade de vida.

A ideia da revista surgiu de uma constatação, a temática qualidade de vida, ao mesmo tempo em que possui um caráter interdisciplinar, não se enquadra no escopo de nenhuma revista brasileira. Várias revistas até publicam artigos do tema, mas essa não é a regra e, em parcela significativa, os artigos publicados trazem a qualidade de vida de forma transversal.

A opção para submetermos os trabalhos que estavam sendo produzidos foi procurar periódicos no exterior, em língua inglesa. Constatamos que mesmo no exterior o número de periódicos era bastante reduzido. Entre os poucos, destaque para Quality of life, Quality of life research, Health and quality of life outcomes e Applied research in quality of life outcomes. É importante observar que, apesar da importância desses periódicos, os mesmos apresentam fator de impacto (JCR) relativamente baixo, inferior a 3.

Para preencher essa lacuna surgiu a ideia de uma revista. Para transformar a ideia em realidade, foi fundamental o auxílio de, na época, um orientado, Bruno Pedroso, que contribuiu significativamente na estruturação da revista e na edição dos primeiros números. Quando concebemos a revista, o fizemos pautado na ideia de não fazermos simplesmente mais uma revista. Estabelecemos a plataforma SEER como meio de divulgação. Desde o primeiro número conferimos 
o DOI para todos os artigos publicados. As normas da revista foram construídas pensando numa indexação futura na base Scielo. O começo não foi fácil, como não é para qualquer revista brasileira que não está no Qualis.

\section{E hoje, depois de cinco anos de circulação ininterrupta, qual a situação da Revista Brasileira de Qualidade de Vida?}

A Revista Brasileira de Qualidade de Vida - RBQV vive um momento bastante distinto do inicial. Como editor sempre procurei estabelecer um padrão de qualidade elevado para a revista, o que não é simples com poucas submissões. Os primeiros números foram disponibilizados com no máximo cinco artigos. Mesmo com o número reduzido de submissões, muitos artigos foram rejeitados antes mesmo de serem avaliados pelos referees.

No primeiro semestre de 2011, quando entravamos no terceiro ano de circulação da RBQV, para fazer seu doutorado, o Bruno, que atuava como editor assistente, pediu para se desligar da revista. Para substituí-lo convidei uma ex-orientada, Camila Lopes Ferreira. A Camila aceitou o desafio e teve competência de dar continuidade no trabalho que vinha sendo muito bem feito, além de aceitar novos desafios que impulsionaram a revista. Entre os desafios, a mudança dos padrões editoriais e novas indexações.

A transição coincidiu com a inserção da RBQV no Qualis. Mesmo em estratos inferiores (B4 e B5), a inserção produziu um aumento significativo nas submissões, mudando o panorama. Esse aumento possibilitou que a periodicidade da revista que era semestral fosse alterada para trimestral. Com o próximo número, o objetivo é indexar a RBQV na base Lilacs, o que, se alcançado, e entendemos que existem possibilidades reais para tal, elevara o Qualis da revista para estratos intermediários, alçando-a para um novo patamar.

Analisando o projeto inicial, diria que estamos onde devíamos estar nesse momento. Mas o projeto é muito maior, e acredito nele. Certamente daqui cinco anos a situação da revista será bastante distinta da atual, apesar das dificuldades em manter uma revista em circulação e dos problemas existentes em uma área não consolidada como a qualidade de vida.

\section{O senhor mencionou problemas na área da qualidade de vida. Quais são esses problemas?}

Vários e de diferentes ordens. Um problema central é que a qualidade de vida enquanto área de especialização é bastante recente, apesar de existirem tentativas de lhe atribuir uma ancestralidade respeitável, através de referências às observações feitas por autores conceituados em diferentes áreas.

O crescimento da área foi muito grande, principalmente depois da década de 70 (o termo qualidade de vida apareceu no banco de dados MEDLINE em 1977). No entanto, o crescimento é fruto, em medida significativa, de especialista de áreas como a administração, educação física, psicologia, enfermagem, entre outras, os quais, devido ao envolvimento com os objetos de suas áreas, não conseguem um distanciamento necessário para a produção de análises fecundas e nem para uma implantação orgânica das preocupações que devem ser centrais na área da qualidade de vida. Pode-se falar, hoje, de quatro abordagens principais: econômica, psicológica, biomédica e geral ou holística.

Os estudos realizados independentemente da abordagem tratam, em última análise, de problemas de outras áreas, com um caráter meramente empirista. Apesar de exceções, pouquíssimos trabalhos produzidos na área de qualidade de vida têm a capacidade de despertar o interesse de pesquisadores de outras áreas. Outro problema grave é a falta de correntes do pensamento teorizando a qualidade de vida. E não podemos falar que a área já tenha uma base teórica consistente. Não tem. 


\section{O senhor poderia falar um pouco dos problemas decorrentes da falta de teorização mencionada.}

O espectro é muito amplo. Poderia iniciar falando da perspectiva histórica apresentada em muitos trabalhos. É recorrente atribuir a origem da ideia de qualidade de vida para Aristóteles, o que é absurdo. Outro absurdo é a tentativa de precisar a primeira vez em que o termo qualidade de vida foi mencionado. Alguns atribuem a menção para Pigou, em 1920, num livro sobre economia e bemestar; outros para o ex-presidente dos Estados Unidos, Lyndon Johnson, quando este, em 1964, declarou que: "os objetivos não podem ser medidos através do balanço dos bancos. Eles só podem ser medidos através da qualidade de vida que proporcionam às pessoas". A autoria não é algo relevante. Além disso, a afirmação é, sobre diversas perspectivas teóricas, uma redução.

Pode-se, por exemplo, pensar com Bourdieu ou Weber a questão do passado de forma muito mais sofisticada. Uma possibilidade é usar a modernidade como baliza distintiva (fronteira móvel) entre o conceito ancestral e moderno. Além disso, essa fronteira certamente não é demarcada como uma data específica como 1920 ou 1964. Com esse enfoque poderíamos estar falando, por exemplo, das conquistas trabalhistas alcançadas após a Revolução Industrial como a progênie da qualidade de vida moderna. Em Weber, também como exemplo, poderiam ser apresentadas algumas características que produziram a modernidade da ideia de qualidade de vida. Certamente apareceriam elementos como secularidade, igualdade, racionalização, entre outros.

Outro problema é conceitual. A maioria dos trabalhos publicados adota o conceito construído pela Organização Mundial da Saúde, no qual a qualidade de vida é a: "percepção do indivíduo de sua posição na vida no contexto da cultura e sistema de valores em que vive e em relação aos seus objetivos, expectativas, padrões e preocupações", mesmo os autores tendo clareza que a qualidade de vida é multidimensional, subjetiva e dotada de elevada complexidade. Particularmente advogo um conceito que saia do individual.

Pode-se falar, ainda, dos poucos instrumentos utilizados nas pesquisas. Mesmo se tratando de instrumentos validados e com propriedades psicométricas satisfatórias, como é o caso do WHOQOL e o do SF-36, a restrição produz uma espécie achatamento da área. De forma ampliada pode-se falar de problemas de método. A falta de uma identidade clara (entendendo identidade como o que uma área produz na pós-graduação) determina a inexistência de métodos próprios de pesquisa. As metodologias empregadas nas pesquisas são emprestadas de outras áreas.

Além disso, por se tratar de uma temática subjetiva, a aplicação de métodos mais distantes dos utilizados nas ciências naturais proporciona limitações na generalização dos resultados. Em suma, são problemas que vão desde o histórico até o método. Em termos práticos, as pesquisas produzidas apresentam limitações.

\section{Quais são as limitações existentes nas pesquisas?}

As limitações são decorrentes de problemas que ocorrem nas diversas etapas da pesquisa. É importante aqui colocar uma distinção feita por Marx, no Posfácio da $5^{\text {a }}$ edição de $\mathrm{O}$ capital. Para Marx, existe um método de pesquisa e um método de exposição. Na construção da pesquisa, o referencial teórico, uma das etapas iniciais da pesquisa, é, normalmente, construído de forma limitada, o que permite o desenvolvimento de uma pesquisa, no máximo, limitada.

Em função de muitos trabalhos que já orientei, ouso apontar também a limitação de muitos pesquisadores brasileiros em ler em inglês como outro problema que fragiliza essa etapa extremamente importante. Mais grave ainda é a utilização de referencias relativamente velhas (com mais de cinco anos), a falta de referências em inglês, a utilização de referências como livros, dissertações, teses e trabalhos publicados em anais de congressos (algumas áreas mais tradicionais 
não aceitam referências que não sejam de periódicos), leituras parciais dos trabalhos referenciados, número limitado de referências, entre outros.

Amostras reduzidas, falta de uma segunda variável de pesquisa (muitos trabalhos tem como variável única a qualidade de vida), emprego de metodologias simplistas para a leitura de problemas complexos, são outros problemas recorrentes. Falando do método de exposição, se a dificuldade de se escrever corretamente em português já é grande, nem se fala em inglês. O artifício utilizado normalmente é o de se pagar por traduções, mas, em função da linguagem técnica, a solução nem sempre se apresenta como satisfatória.

\section{A qualidade de vida no trabalho é uma área que vem ganhando espaço no meio} acadêmico. $O$ senhor entende que se trata de um modismo passageiro ou de algo que permanecerá como objeto de estudo daqui algumas décadas?

É sempre difícil para um pesquisador falar do futuro. O pesquisador sempre se debruça sobre o passado e/ou presente, nunca sobre o futuro. Mas, mesmo assim, tentarei traçar algumas considerações em relação ao que foi perguntado.

Inicio dizendo que a qualidade de vida no trabalho - QVT nada mais é que um enfoque específico da qualidade de vida. Pode-se, por exemplo, falar de qualidade de vida fora do trabalho ou no lazer. Em vários estudos falta essa clareza. Agora, a vertente ganhou importância por que a parcela mais significativa do tempo do indivíduo na sua vida produtiva é passada no ambiente de trabalho.

Se pensarmos que a jornada de trabalho é de oito horas diária, mais uma hora para almoço, mais o tempo gasto no deslocamento para o trabalho, estamos falando de algo em torno de dez horas diárias. Em muitos casos é até mais que isso. Dessa forma, é normal a atenção que está sendo dada. Penso que se trata de uma tendência irreversível, e não um modismo, apesar de equívocos que existem. O maior deles é a associação mecânica de políticas de QVT com o aumento da produtividade. Definitivamente a QVT não deve buscar esse aumento. E, lamentavelmente, muitos pesquisadores aceitam a situação como natural.

\section{O senhor gostaria de acrescentar mais alguma coisa?}

Precisamos começar a dialogar com o mundo. A receita é conhecida de todos. Se não o fizermos pagaremos um preço muito alto num futuro próximo. Agora, para que esse diálogo aconteça precisamos avançar muito e rápido. Encerro agradecendo a oportunidade. 